\title{
Online Quizzes: A Self-Conscious Exploration of Strategic Trade-offs in the Middle East
}

\author{
Norman S. Wright \\ Zayed University \\ norman.wright@zu.ac.ae \\ Rodney Redding \\ rrseminar@msn.com
}

\author{
Marwah Eltom \\ Promoseven Weber Shandwick \\ marwah.eltom@promoseven.com
}

\begin{abstract}
This study examines the transition in an Arabian Peninsula university context from traditional, in-class pen-and-paper quizzes to online quizzes. While research shows that quizzes can play an important role in student learning, the outcomes from online quizzes are not clear. Our research shows that the learning contribution of online quizzes depends on the form of online quizzing employed; yet the decision to use online quizzes is often influenced by other administrative objectives such as cost efficiencies, convenience, and public relations benefits. Given these findings, the paper highlights the importance of matching administrative priorities with one's approach to learning and teaching when moving toward greater use of computer technology in coursework.
\end{abstract}

\section{The Push For Online Learning}

Information technology has made its presence felt in health care, government, manufacturing, tourism, and other industries. Higher education has also felt the impact of new information technologies in the form of online lecture notes, discussion boards, and assessment activities. Indeed, in many contexts online content delivery and course management are rapidly becoming the norm rather than the exception. Students entering universities or colleges have now come to expect or even demand the use of such technologies in their courses.

Statistics from the Sloan Consortium (Allen and Seaman, 2006) indicate that some 3.2 million United States students were taking one or more online courses during fall semester of 2005 . This represents an increase of over 800,000 students compared with the previous year. Many reasons are given for this shift towards electronic forms of learning, including increased student convenience, decreased costs, public relations (competitive) benefits, and, most importantly, improved student learning outcomes.

In terms of student convenience, electronic availability of course material increases the ease with which it can be accessed from various locations including home, work, campus, and during the commute to

Wright, N.S., Redding, R. \& Eltom, M. (2007). Online Quizzes: A Self-Conscious Exploration of Strategic Trade-offs in the Middle East. Learning and Teaching in Higher Education: Gulf Perspectives 4(2). 
and from university (Stith, 2000). Additionally, online education helps geographically remote students to join reputable universities without having to relocate and undergo a major lifestyle change (Tham \& Werner, 2005).

Beyond enhancing student convenience, the use of information technology in teaching can lead to cost reductions of $20 \%$ to $65 \%$ (Lewis et al, 1985) assuming that the cost of purchasing, installing, and maintaining the required software is outweighed by increased revenues (McInnes et al, 1995).

Further, administrators also see the use of information technology for learning as a competitive advantage in enhancing an institution's reputation. Tham and Werner (2005) caution, however, that educators may become so enamored with the technology that they lose focus of their main objective, enhancing student learning - thus potentially compromising their reputation.

Finally, online learning is often touted for its ability to improve learning outcomes. Information technology can facilitate the interaction of students with their peers and faculty by removing communication barriers while catering to a larger variety of learning styles and encouraging greater selfdirected learning (Tham \& Werner 2005; Karakaya et al, 2001; Sanders and Morrison-Shetlar, 2001). Due to such technologies, student dependence on teachers has considerably decreased, changing the role of instructors towards greater facilitation. Beyond these benefits, some faculty also use techniques such as online quizzes and exams to reduce the pressure and tension that generally builds in traditional classroom settings (Sanchis, 2001). This may be seen as particularly important in Gulf countries where many students may be the first in their families to attend university.

\section{The Role of Quizzes in Learning}

Student preparation outside of the classroom has long been associated with performance inside the classroom (Vruwink and Otto, 1987; Baldwin 1980). In particular, quizzes can be a means of increasing comprehension, attendance, classroom participation, and even self confidence (Warnock, 2004).

Wilder et al (2001), for example, found that student attendance increased with the use of random extra credit quizzes. While the experimental design was not such that a relationship between the use of random, extra credit quizzes and class performance could be shown, the authors did find a positive correlation between quizzes, attendance, and course scores. This suggests that the use of quizzes leads to better overall course performance.

Other studies have found that giving quizzes immediately after a lecture or reading increases material retention in later testing (Kardash et al, 1988). This may be the case for several reasons including increased attention paid during lectures and motivation for students to overcome procrastination (Tuckman, 1996).

Additional studies indicate that the implementation of weekly quizzes, compared to quizzes administered at greater intervals, enhances student performance on final exams and overall class performance (Mazlo et al, 2002; Gaynor and Millham, 1976; Martin and Srikameswaran, 1974; Mahwinney et al, 1971). Of course some of this difference may be accounted for by grading design. Elikai and Baker (1988) found that only when points assigned to quizzes represent a significant portion of the overall grade will students be motivated to perform. Note also that at least one study (Vruwink and Otto, 1987) found no relationship between quizzes and exam performance.

Overall, then, in the traditional literature on quizzes there is a plausible relationship between the use of quizzes and student performance. Evidence for the effectiveness of quizzes in motivating behavior is

Wright, N.S., Redding, R. \& Eltom, M. (2007). Online Quizzes: A Self-Conscious Exploration of Strategic Trade-offs in the Middle East. Learning and Teaching in Higher Education: Gulf Perspectives 4(2). 
less available, however, for online quizzes. McKelvy (2000) found evidence that moving from traditional pre-laboratory preparation to online quizzes resulted in lower levels of performance among chemistry students.

Bushway and Flower (2002) used a quasi-experimental design to examine the impact of online technology on failure rates and withdrawal rates in a criminal justice statistics course. They found that both online supplemental instruction and online quizzes decreased failure rates. Further, both of these online interventions increased the performance of those students who remained in the class. An important element of this study is that the students taking the quizzes had previously been identified as "at-risk" students. Further, the authors found a correlation coefficient of .55 between quiz performance and final grade for those who remained in the course.

The link between test scores and quizzes is further confounded in a study by Klass and Crothers (2000) who found no significant differences on exam performance between students who completed webbased quizzes and those who did not.

In summary, the relationship between online quizzes and exam performance is mixed. Much of the literature emphasizes the positive outcomes associated with adopting information technology in the learning process. Less attention seems to be given to the unintended negative consequences associated with online approaches to learning. As administrators are increasingly exposed to the benefits of such technology, they may encourage faculty to adopt information technology in coursework without due consideration to the trade-offs involved. This paper examines one aspect of the online experience, quizzes, in a Gulf context. By better understanding these trade-offs, faculty and administrators can make more informed decisions on the use of information technology for higher learning in the Gulf Region.

\section{The Case Study}

During the spring semester, 2004, the Introductory Financial Accounting course at our university, on the recommendation of the Dean at the time, began to use Blackboard for communication with students and for posting solutions to assignments. Quizzes for the course, however, were given in class on paper. Ten quizzes were administered each course, and the results represented $10 \%$ of the course grade. The paper quizzes administered in each section used the same questions but usually in four versions with the questions and answers in different orders.

At the beginning of Fall semester, 2004, a faculty meeting was held during which the topic of migrating faculty to greater online involvement was discussed. In particular, an online quizzing initiative was introduced for discussion. Several professors voiced concern regarding the initiative, noting that putting quizzes online would make cheating harder to control. While acknowledging the validity of this concern, the administrator supporting the initiative indicated that in order to cheat, students would at least have to open their books to look up the answers, which he felt would be greater preparation than many students were doing for class at the time.

Despite the concerns of many faculty members and the short time line to the beginning of class (one week), it was decided that online quizzes would become mandatory for the upcoming semester. While several "water cooler" conversations indicated that some professors quietly undermined the initiative through non-participation, others complied with the mandate. The latter group included faculty members teaching Introductory Financial Accounting.

Wright, N.S., Redding, R. \& Eltom, M. (2007). Online Quizzes: A Self-Conscious Exploration of Strategic Trade-offs in the Middle East. Learning and Teaching in Higher Education: Gulf Perspectives 4(2). 
Four different professors were assigned to teach the course, with one acting as coordinator. The Introductory Accounting faculty agreed to once again give ten quizzes to represent $10 \%$ of the course grade. Each quiz consisted of five to ten questions with the majority containing ten. In contrast to the classroom quizzes of the previous semester, these quizzes were to be administered through Blackboard.

The course coordinator volunteered to make up the quizzes from the textbook test bank. The quizzes were taken by all sections in the course in a two hour window outside of the normal class period. Students logged in and had ten minutes to complete the quiz. The questions administered to each student were the same questions but presented in random order, with the possible answers also randomized by Blackboard. Students were required to answer one question at a time and were not allowed to go back to a previous question. They were also not allowed to restart a quiz.

A two hour time frame was allowed for completing the quiz for two reasons. First, it was unclear whether the university computer system could handle 240 students accessing Blackboard and the quiz simultaneously. Second, computer labs available were not large enough to handle all 240 students at once.

For this study, data were collected from two different samples during different semesters. The first sample consists of quiz and exam scores from fifty five students who had taken traditional paper quizzes in the classroom. The second sample consists of ninety nine students from the following semester who took the quizzes online as described previously. Both groups were taught by the same instructor.

\section{Results}

In attempting to assess the validity of the claim that students taking online quizzes would use their texts during the quizzes, and hence improve their performance in the class, we ran an analysis of the correlation between quiz scores and exam scores. While the design of the study cannot conclusively demonstrate the relationship, the data do not support the champion's proposition.

The correlation between a student's average quiz scores and average exam score was calculated for each sample. The average quiz score represents the average of all quizzes the student actually took during the course of the semester. Some students missed one or more quizzes during the semester for various reasons. These scores were omitted to give an indication of actual quiz performance rather than quiz performance as affected by attendance, computer problems, or other non-knowledge- based issues.

The average exam score consists of scores on two midterms and a comprehensive final exam. In the traditional sample, each midterm was worth $25 \%$ with the final exam being worth $35 \%$. In the online quiz sample, two midterms worth $25 \%$ each were administered along with a third midterm at $15 \%$. Additionally, a final exam worth $20 \%$ of the overall grade was also administered. In both samples, midterms and finals constituted $85 \%$ of the overall grades. Whether weighted exam scores or nonweighted exams scores are used, the results remain consistent. In the sample where traditional, in-class quizzes were given to students, the correlation between the average quiz score and the average unweighted exam score is $.721(p<.001)$. The correlation between average quiz score and average weighted exam score is 689 ( $p$ <.001). In both cases, there is a clear relationship between student performance on quizzes and exams.

In the online quiz sample, the correlation between the average quiz score and the average unweighted exam score is 129 (not significant). The correlation between average quiz score and average weighted

Wright, N.S., Redding, R. \& Eltom, M. (2007). Online Quizzes: A Self-Conscious Exploration of Strategic Trade-offs in the Middle East. Learning and Teaching in Higher Education: Gulf Perspectives 4(2). 
exam score is similar at 124 (not significant). In contrast to the situation where quizzes were administered in the classroom, there is no significant relationship between quiz scores and exam scores.

The explanation for this lack of correlation became readily apparent as our student co-author conducted personal interviews with several members of the class. These students indicated that in the class with online quizzes cheating was widespread and took on forms different than simply opening a textbook to look up an answer as suggested by the administrative champion. These included multiple students taking the quiz at the same time and looking up one answer and then sharing it with their colleagues. Further, students sometimes acquired the services of a more knowledgeable substitute to take the quiz in their place. These abuses took place not only off campus but within computer labs on campus as well.

Others managed to bypass the system controls, printing a quiz to share with their friends who had not yet taken it. One student indicated that this can be done by photographing the screen with a mobile phone and then sending the picture to a computer account to be printed. Or, it can be done by entering Photo Editor and taking a snapshot of the screen and pasting it to another file. Undoubtedly, these are not the only ways in which online quizzes can be copied and printed for distribution.

\section{Discussion}

This experience reinforces the idea that many students, given the opportunity, will cheat in order to improve their score in a class. While this is not unique to the Gulf region, it is definitely an issue for educators in the region. This experience also highlights the fact that students frequently understand online technologies better than administrators and professors. Neither of these findings, we suspect, will catch the academic community by surprise.

Being embarrassed at having adopted the recommendation to employ online quizzes in such a naïve manner, and in an effort to improve our performance, we sought out best practices from other schools. We did so by conducting a review of university websites as well as a review of a Blackboard discussion board addressing issues of cheating in the online environment. A wide range of institutions were included in the review including:

7 public universities with enrollment of greater than 10,000 students

5 public universities with enrollment of less than 10,000 students

6 private universities or colleges

2 community colleges.

Of the twenty institutions all had websites with information for faculty about the use of Blackboard. In general, it appears that most higher education institutions are providing guidance to their faculty on the technical use of Blackboard, such as how to set up a course and use features such as Gradebook. Topics Identified included:

- Have student sign an agreement that they won't cheat.

- Take steps to know if the right student is on line.

- Proctor on-line exams in a lab setting.

- Randomize questions.

- Offer a CPE course for faculty instruction techniques including cheating advice.

Wright, N.S., Redding, R. \& Eltom, M. (2007). Online Quizzes: A Self-Conscious Exploration of Strategic Trade-offs in the Middle East. Learning and Teaching in Higher Education: Gulf Perspectives 4(2). 
- Use ways to prevent students from printing the on-line quiz for other student use.

- Make the quizzes worth only a minor portion of grade.

- Set time limits for quizzes.

Interestingly, fifteen of the twenty institutions specifically addressed the issue of Blackboard use and student cheating. The guidance provided on cheating and online assessment varied greatly among schools. Some websites had as little as one sentence addressing cheating. Two went so far as to offer continued professional education seminars for faculty to address the issue. None, however, linked these discussions to specific organizational objectives in a way that clearly illuminates the trade-offs in the approach employed.

In addition to exploring online university websites, we also accessed a discussion group housed within the Blackboard site. Data from both sources indicate three fundamental approaches to resolving cheating in online quizzes. These best practices suggest that faculty either 1 ) decrease cheating by proctoring quizzes, 2 ) reduce the importance of quizzes on the overall grade so as to minimize the rewards to cheating, or 3 ) encourage students to act with academic integrity through the establishment of an honor code system.

The most often mentioned approach to controlling cheating with on line quizzes was to proctor the quiz in a lab setting. While this is possible for students who are physically attending the institution it is not convenient for those who are taking the course remotely. Some schools suggested using certified testing centers where available to overcome this issue. This approach is particularly effective in eliminating students sharing answers with one another, printing out the quiz questions, and having others take the quiz for them.

Within the proctored environment, there exists a debate on the use of randomized questions. One large public university stresses that while proctoring was the most important aspect of Blackboard testing, randomizing questions can also decrease cheating. Another large private university, however, discourages the use of randomized questions which can lead to statistical unfairness in grading.

Neither site clarified their definition of randomization which can mean selecting randomly for each student a set number of questions from a larger pool of questions or using the same questions for each student but randomizing the order of presentation and/or the order of answers. Both of these randomizing approaches are available on Blackboard.

Given that proctoring online quizzes decreases convenience, others recommend decreasing the weight placed on online quizzes in the overall grading scheme. While this clearly improves the validity of the grades and decreases the rewards for cheating, it may also decrease the motivation of students to study regularly throughout the semester which was the very reason for implementation at our institution.

Finally, both sources also suggest that universities can establish ways of appealing to the higher values of students through some kind of honor code. One school does not allow students to take an online quiz until they have verified that they have read, understood, and agreed to follow the school's honor code. Personal experience of the authors with two different schools employing honor codes suggest that such an approach will not eliminate or even significantly decrease cheating on online quizzes.

In summary, each approach has benefits but also a significant downside. In the case of proctored quizzes, convenience is diminished. In the case of reducing the weight placed on online quizzes, student motivation may be decreased. Finally, in the case of employing honor codes, the problem of cheating is unlikely to disappear. Unfortunately, the guidelines given to faculty and in many online discussion groups do not specifically acknowledge these trade-offs in a framework that can guide behavior.

Wright, N.S., Redding, R. \& Eltom, M. (2007). Online Quizzes: A Self-Conscious Exploration of Strategic Trade-offs in the Middle East. Learning and Teaching in Higher Education: Gulf Perspectives 4(2). 


\section{Conclusions}

While this study certainly suffers from some design issues such as convenience sampling and potentially confounding variables, the results do seem to support our own experience and that of many professors. Experience shows that a certain group of students will always be interested in circumventing assessment systems despite the impact on their own learning.

Keeping this in mind becomes important as many faculty are being encouraged and, in some cases, pressured to implement online pedagogical approaches for a variety of reasons including cost reductions, student and faculty convenience, competitive advantages and public relations gains, and enhanced learning outcomes. As our research shows, online quizzes can add value in each of these areas. However, it appears that current technology does not allow all four to be achieved at the same time. As a result, when considering the opportunities provided by online quizzes, it is important to keep in mind the main goal to be accomplished as well as the fact that achieving that goal may come at a cost in another area.

As a result, when considering the opportunities provided by online quizzes, administrators and faculty should keep in mind the main goal to be accomplished as well as the fact that achieving that goal may come at a cost in another area. If, for example, improved learning outcomes are the main objective, proctored quizzes that account for a significant portion of the final grade may be the best strategy. In proctoring the exams the probability of cheating decreases, and large rewards enhance the motivation to study. At the same time, however, student convenience will not be realized. If the main objective, on the other hand, is to make coursework more convenient for students and faculty, proctored quizzes are ineffective. The downside to unproctored quizzes, however, is increased cheating and decreased student motivation to study.

As these two brief examples demonstrate, simultaneously reaching the four goals of enhanced convenience and learning outcomes, decreased costs, and public relations enhancement is not possible given the current state of technology. Further, such technology does not appear to be on the immediate horizon. Therefore, our recommendation to faculty and administrators faced with either the pressure and/or the opportunity to employ online assessment is simply to be very clear on the main outcome desired and the trade-offs incumbent in reaching that goal. In so doing, high priority goals can be maximized while limiting some of the costs associated with online quizzes.

From a more personal perspective, this experience reinforced the idea that the pressures faced by administrators are sometimes different than those faced by professors. This results in a certain goal divergence that needs to be remedied if the institution is to move forward in a unified manner. The case study strengthened the resolve of the lead author, who now plays a more administrative role, to facilitate such pedagogical discussions, as well as that of the second author to demand the same.

\section{Authors}

Dr. Norman Wright is currently transitioning from Zayed University in Dubai to the ABTI American University of Nigeria, where he will serve as Dean of the School of Entrepreneurship and Business Management. His current research focuses on entrepreneurial activities in and around conservation zones as well as cross-cultural team dynamics.

Dr. Rodney Redding has recently moved into semi-retirement to spend more time with his grandchildren. Having worked around the world including the United Arab Emirates, Kenya, and Georgia, he has settled in Florida where he provides continuing professional education courses to

Wright, N.S., Redding, R. \& Eltom, M. (2007). Online Quizzes: A Self-Conscious Exploration of Strategic Trade-offs in the Middle East. Learning and Teaching in Higher Education: Gulf Perspectives 4(2). 
accountants with Rodney Redding Seminars. His current research examines success factors of the Penn State football program.

Marwah Eltom is a Senior Account Executive at Promoseven Weber Shandwick (PWS), Abu Dhabi. A graduate of Marketing and Management from the American University of Sharjah, Marwah joined PWS in November 2005. She currently handles PR accounts for various clients including Marina Mall, Daman Insurance, and Abu Dhabi Health Authority.

\section{References}

Allen, I.E., and Seaman, J. Making the Grade: Online Education in the United States, 2006. Sloan Consortium: Needham, Massachusetts, 2006

Baldwin, B. (1980). On positioning the quiz: An empirical analysis. The Accounting Review 55(4): 664671.

Bushway, S.D. and Flower, S.M. (2002). Helping criminal justice students learn statistics: A quasiexperimental evaluation of learning assistance. Journal of Criminal Justice Education 13(1): 35-56.

Elikai, F. and Baker, J. (1988). Empirical evidence on the effectiveness of quizzes as a motivational technique. Issues in Accounting Education 3(2): 248-254.

Gaynor, J. and Millham, J. (1976). Student performance and evaluation under variant teaching and testing methods in a large college course. Journal of Educational Psychology 68: 312-317.

Karakaya, F., Ainscough T.L. and Chopoorian, J. (2001). The effects of class size and learning style on student performance in a multimedia-based marketing course. Journal of Marketing Education 23(2): 84-90.

Kardash, C.M., Lukowski, L., and Bentmann. (1988). Effects of cognitive styles and immediate testing on learning from a lecture. Journal of Educational Research 81(6): 360-364.

Klass, G. and Crothers, L. (2000). An experimental evaluation of web-based tutorial quizzes. Social Science Computer Review 18(4): 508-515.

Lewis, D.R., Dalgaard, B.R. and Boyer, C.M. (1985). Cost Effectiveness of Computer-Assisted Economics Instruction. American Economic Review 75(2): 91-96.

Mahwinney, V.T., Boston, D.E., Laws, D.L., Blumenfeld, G.J., and Hopkins, B.L. (1971). A comparison of students studying-behavior produced by daily, weekly, and three-week testing schedules. Journal of Applied Behavior Analysis 12: 257-264.

Martin, R.R. and Srikameswaran, K. (1974). Correlation between frequent testing and student performance. Journal of Chemical Education 51(7): 485-486.

Mazlo, J., Dormedy D., Niemoth-Anderson, J., Urlacher,T., Carson, G., Haas, E., and Kelter, P. (2002). What motivates students in the Lab?: Assessing motivational methods in the general chemistry lab. Journal of College Science Teaching 31(5): 318-311.

Mclnnes, W.M., Pyper, D., Van Der Meer R. and Wilson, A. (1995). Computer-aided learning in accounting: educational and managerial perspectives. Accounting Education 4(4): 319-334.

McKelvy, G. (2000). Pre-Laboratory Information and Assessment using WebCT. Paper presented at WebCT Conference, July 2000, Athens Georgia.

Wright, N.S., Redding, R. \& Eltom, M. (2007). Online Quizzes: A Self-Conscious Exploration of Strategic Trade-offs in the Middle East. Learning and Teaching in Higher Education: Gulf Perspectives 4(2). 
National Postsecondary Education Cooperative. How does Technology Affect Access in Postsecondary Education? What Do We Really Know? (NPEC 2004-831), prepared by Ronald A. Philips for the National Postsecondary Education Cooperative Working Group on Access-Technology Washington, DC: 2004.

Sanchis, G.R. (2001). Using Web forms for Online Assessment. Mathematics and Computer Education 35(2): 105-113.

Sanders, D.W. and Morrison-Shetlar A.I. (2001). Student attitudes toward web-enhanced instruction in an introductory biology course. Journal of Research on Computing in Education 33(3):251-262.

Stith, B. (2000). Web-enhanced lecture course scores big with students and faculty. The Journal 27(8): 20-25.

Tham, C.M. and Werner, J.M. (2005). Designing and Evaluating E-Learning in Higher Education: A Review and Recommendations. Journal of Leadership and Organizational Studies 11(2): 15-25.

Tuckman, B.W. (1996). Using spotquizzes as an incentive to motivate procrastinators to study. Paper presented at the Annual Meeting of the American Educational Research Association. New York, New York, April 1996.

Vruwink, D.R. and Otto, J.R. (1987). Evaluation of teaching techniques for introductory accounting courses. The Accounting Review 62 (2): 402-408.

Warnock, S. (2004). Quizzes boost comprehension, confidence. Teaching Professor 18(3): 5.

Wilder, DA, Flood, WA. and Stromsnes, W. (2001). The use of random extra credit quizzes to increase student attendance. Journal of Instructional Psychology 28(2): 117-120.

Wright, N.S., Redding, R. \& Eltom, M. (2007). Online Quizzes: A Self-Conscious Exploration of Strategic Trade-offs in the Middle East. Learning and Teaching in Higher Education: Gulf Perspectives 4(2). 